\title{
0746 NON FATAL INTENTIONAL INJURIES AMONG WOMEN AND CHILDREN
}

M W Zaffarullah*, H M A H Karunaratne Correspondence: Teaching Hospital, Anuradhapura, Sri Lanka, 66, Dhammadassi Mawatha, Kandy, Sri Lanka

\subsection{6/ip.2010.029215.746}

We estimated the incidence of intentional injuries occurring between June to November 2009 in the district of Anuradhapura, Sri Lanka having a mid year population of 755 000 which result in 113 persons in sq $\mathrm{km}$. Head and neck injuries have been found to be a main cause for hospital admissions due to assaults. The mean age of the victims was 29.25 years. The commonest area that was assaulted were ears (80.6\%). More than $80 \%$ of victims were assaulted with hand and $95 \%$ of the assailants were known to the victims. The assailant was under the influence of alcohol in more than $78 \%$. Of the victims $22.2 \%$ had history of previous assaults. The rate of intentional injury was directly correlated with both the degree of illiteracy and the poverty level of the community of residence. We conclude that intentional injuries are relatively common in this population and that attempts to prevent them must be directed to the women and children who are at greatest risk. 